\title{
Sputum and mucociliary clearance mechanisms
}

\author{
LYNNE REID \\ M.D., F.R.C.P., F.R.A.C.P., F.R.C.Path. \\ Cardiothoracic Institute, Brompton Hospital, Fulham Road, London S.W.3.
}

Summary

Bronchial secretion forms a periciliary liquid layer and may also give rise to thicker secretion that moves on the tips of the cilia. This latter material as collected at bronchoscopy or coughed up as sputum is a viscoelastic substance behaving in a characteristic way over a wide range of shear rates. The anatomical basis of secretion is described and its control as established by organ culture.

SPUTUM production represents an excessive production of bronchial fluid-particularly of its mucus component. The practical problem the chest physician would wish to control is to ensure its clearance but even more to reduce its production to normal levels. As you already know, we are not in a position to suppress completely the production of mucus in normal airways, much less in those with hypertrophy of the glands because of disease.

I shall begin with the mucociliary escalator, then discuss viscosity and its measurement, relate these to chemistry, deal with the control of the structures responsible for mucus production and finally say something about new work on the airway epithelium which is giving us some idea of the cells that contribute to the mucociliary escalator.

Serum is strikingly different from sputum. Five millilitres of serum yield five times as much macromolecular dry weight as the same volume of sputum, but at low shear rates sputum is ten times as viscous which means that it is a substance with peculiar properties.

Whole sputum, of course, is such a mixture that it is not surprising that chest physicians and pharmacologists have not been able to produce the ideal cough mixture (Reid, 1970). Bronchial secretion consists of tissue fluid transudate as well as mucus secreted from special cells, both in the submucosal gland and the surface epithelium. From each type of cell, the secretion is glycoprotein, some cells producing a neutral one but most producing an acid.

Whereas in the acid glycoproteins of connective tissues the acid radicle is either a sulphate or hyaluronic acid, in the glycoprotein of epithelial secretions the acid radicle is sulphate or sialic acid. It is probable that sialic acid is the most important

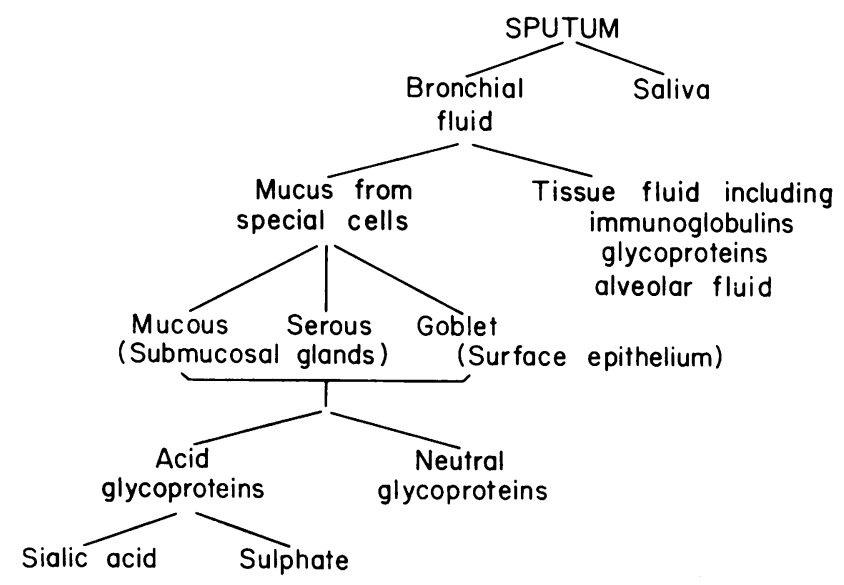

FIG. 1. The constituents of sputum are a mixture (Charman et al., 1974) (reproduced by kind permission of the Editor of British Journal of Diseases of the Chest). 
single component in relation to sputum viscosity. While there is a correlation between viscosity and overall macromolecular dry. weight, between viscosity and immunoglobulins, the most critical single component is sialic acid. This is an amine sugar that includes a carboxyl acid radicle.

\section{Mucociliary escalator}

The term 'mucus blanket' is widely used in the literature but it is well to remind ourselves that the normal airways are empty of secretion. The mucociliary escalator will move sticky mucus but this is disposed in plaques or in gobs which move on the surface of the cilia. A scanning microscope picture of the surface epithelium shows just how irregular this surface is owing to the variety of cell types. The periciliary liquid layer confers a smoothness on the surface along which foreign material, such as mucus or particles, can move. Control of the amount of liquid surrounding cilia must be very delicate because excess would mean that material on the surface moved inefficiently, too little that cilia became entangled in the viscous layer on the surface (Reid, 1973a).

Relatively little is known about the balance and interaction between the periciliary liquid layer and the thick mucus that is moved quite fast on its surface. Active research is continuing in this field. The work of Iravani and van As (1972) shows that secretion comes out in small drops which coalesce to form plaques or 'rafts' as they call a larger collection.

\section{Viscosity of sputum}

In discussing sputum viscosity it is well to appreciate that no one has yet collected separately the periciliary liquid from the surface layer. While sputum doubtless contains the sticky secretions from the special cells, it is not known how much periciliary liquid is included.

Honey is thicker than water, but how do we measure its viscosity? In the case of sputum, a nonNewtonian fluid, a cone and plate system is probably the most satisfactory method of measurement. The material under test is placed between two platens, one a cone, the other a plate; this is a simple device to determine that the shearing stress applied throughout the liquid is the same.

By rotating one of the platens, stress is set up within the liquid which is then conducted to the other platen. The force applied is designated 'shear rate', the effect the 'shear stress'; shear stress divided by shear rate gives the viscosity.

In our Department we have measured viscosity with both the Ferranti-Shirley Viscometer and the Weissenberg Rheogoniometer (Sturgess, Palfrey and Reid, 1970, 1971). The first was developed at the Shirley Institute in Manchester to measure the
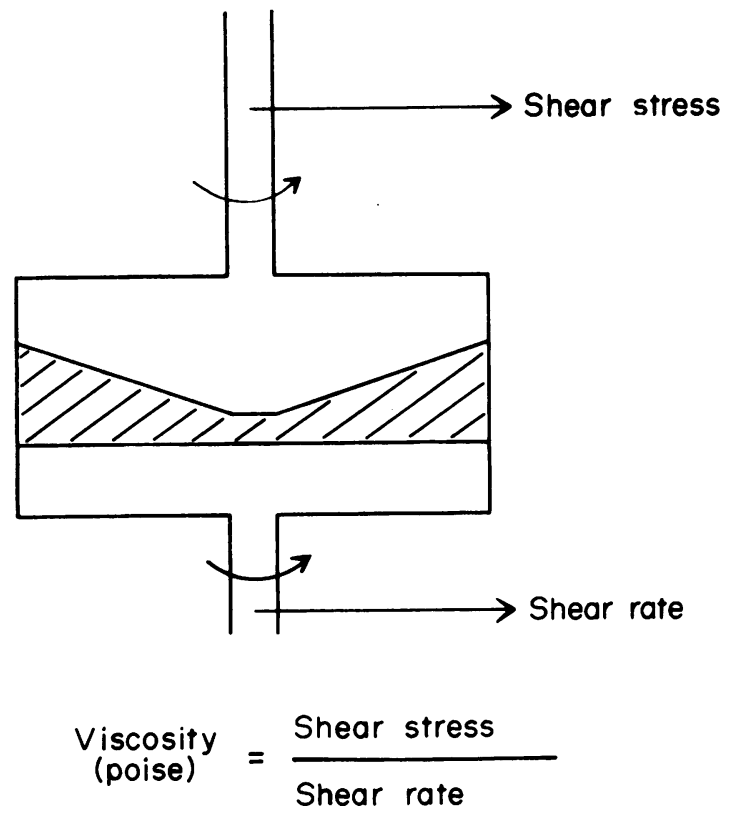

Fig. 2. Diagrammatic representation of a cone and plate viscometer. The fluid under test (shaded) is placed between the two platens.

viscosity of rayon and is widely used in industry The more sophisticated instrument, the Weissenberg Rheogoniometer, was developed in Kent during the last war to measure viscosity of flamethrowing substances. The latter can apply extremely delicate stress and it also has the advantage that oscillation or rotation can be used. By using oscillation it is possible to determine elasticity as well as viscosity.

Sputum is a visco-elastic substance. Elasticity has to do with recovery after deformity, that is recovery after shearing. In sputum it only happens at low shear rates (Mitchell-Heggs, Palfrey and Reid, 1974). In a Newtonian fluid, if viscosity is plotted against shear rate, a straight line is obtained, the viscosity of the liquid being the same at any shear rate tested. Sputum, like most biological fluids, is non-Newtonian, its viscosity varying according to the shear rate at which it is determined. Sputum shows the phenomenon of shear thinning-with increased shearing the viscosity is reduced.

If sputum viscosity is tested over a range of shear rates certain characteristic features emerge (Sturgess et al., 1971; Charman et al., 1974). One of the striking features of the rheological or flow behaviour of sputum is the appearance of a region of fluctuating viscosity at about $0.1 \mathrm{sec}^{-1}$ (Fig. 4). The viscosity is relatively high at lower shear rates and the effect of shearing is relatively slight. The region of fluctuating 


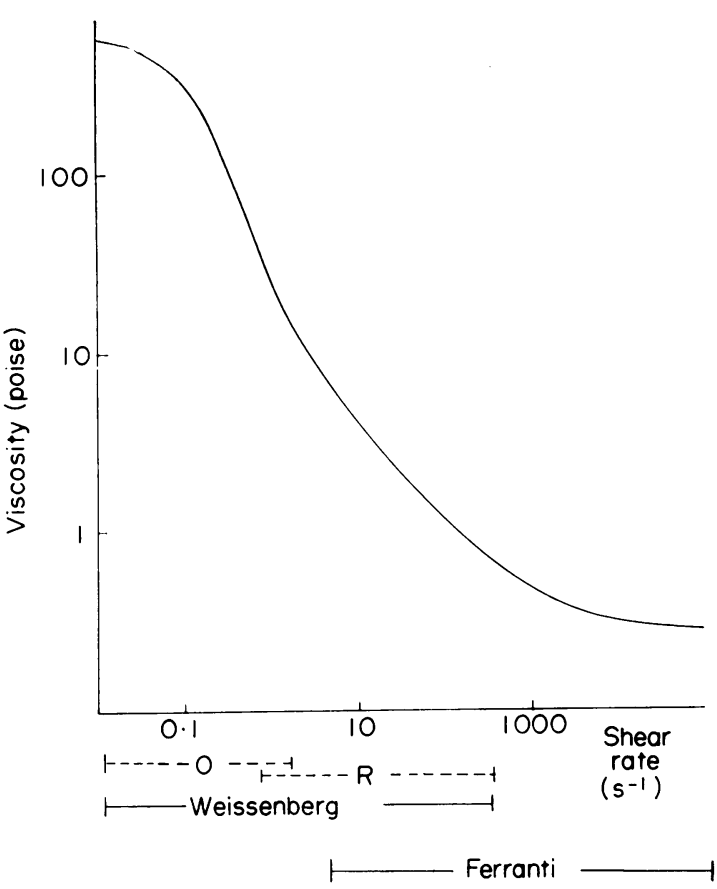

FIG. 3. Sputum viscosity over a range of shear rates A summary of the four zones that can be distinguished in the viscosity plot.

Zone 1 (up to $0.5 \mathrm{sec}^{-1}$ ). Zone 1 includes a region of fluctuating viscosity that gives a notched plateau in the plot; this occurs about $0.1 \mathrm{sec}^{-1}$ but is complete by $0.5 \mathrm{sec}^{-1}$. Up to this shear rate the effect of shearing produced little change in viscosity (Mitchell-Heggs, Palfrey and Reid, 1971; Reid, 1970; Sturgess et al., 1970).

Zone 2 (end of notched plateau up to $10 \mathrm{sec}^{-1}$ ). After the notched plateau the sputum becomes more susceptible to shearing - the reduction in viscosity occurs at a faster rate.

Zone 3 (between 10 and $200 \mathrm{sec}^{-1}$ ). Shearing between 10 and $200 \sec ^{-1}$ is associated with a steady fall in viscosity. In the early part of this range sputum is at its most susceptible to shearing.

Zone 4 (above $200 \mathrm{sec}^{-1}$ ). In the fourth zone, the effect of shearing is much less and, finally, the sputum can be regarded as a Newtonian fluid-a suspension/solution of its various constituents, now degraded. By now some depolymerization has probably also occurred. (Charman et al., 1974) (reproduced by kind permission of the Editor of British Journal of Diseases of the Chest).

viscosity we have called the 'notched plateau'. In mucoid or purulent sputum and in sputum from any disease this plateau region occurs at about the same level of shear. This suggests that it is a feature of sputum. If the sputum is sheared initially at a higher rate this plateau is destroyed. The addition of urea, the breaker of hydrogen bonds, reduces the level of viscosity and makes the plateau less obvious.

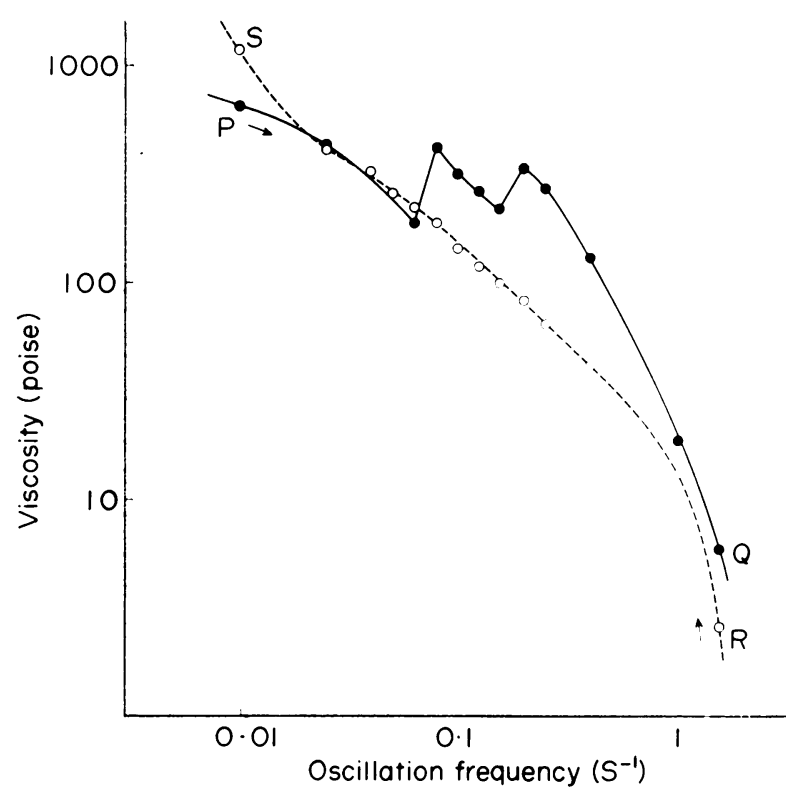

Fig. 4. Zones 1 and 2. Sputum tested at ascending shear rates, $P Q$, show a notched plateau-a region of fluctuating viscosity. This is destroyed by shearing as it is not apparent in another aliquot tested at descending shear rates, R.S. (Charman et al., 1974) (reproduced by kind permission of the Editor of British Journal of Diseases of the Chest).

It is of interest that this region is found in nasal and gastric mucus but not in the cervical mucus of pregnancy or in synovial fluid.

At shear rates above that at which the plateau is displayed the secretions are more susceptible to shearing, which means that viscosity reduces more rapidly as shear rate rises.

Another interesting feature of sputum is that after minimal shearing at low rate, allowing it to stand between the platens produces a rapid increase in viscosity. An eighty-fold increase is found if secretion is left between the platens for $1 \mathrm{hr}$ after a minimal degree of shearing (Fig. 5). This would not be produced even by an extreme degree of drying and certainly not by leaving the material between the platens.

We know little about the levels of shear rate applied under physiological conditions within the airway but it is certainly likely that low shearing and retention of secretion may happen, and may well be a contributing factor to the high viscosity found sometimes in sputum in asthma.

In only one condition have we found a spontaneous increase in viscosity; this is in patients with bronchorrhoea or pituitous catarrh (Lopez-Vidriero et al., 1975). The secretion from these patients is like egg-white, that is, it is not purulent. Whereas a 


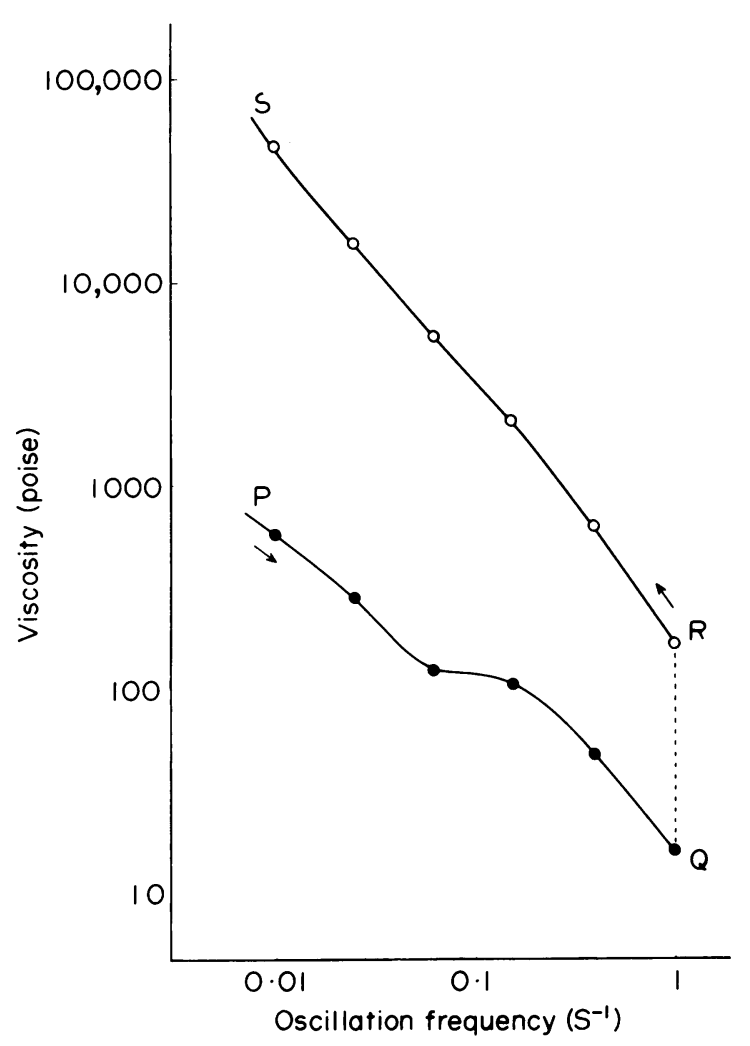

Fig. 5. One aliquot of sputum tested $P Q$ and then RS but left between the platens for $1 \mathrm{hr}$ at $\mathrm{QR}$. A timerelated increase in viscosity occurs (Charman et al., 1974) (reproduced by kind permission of the Editor of British Journal of Diseases of the Chest).

mucoid sputum can stand on the bench at room temperature for perhaps 4,6 and even $12 \mathrm{hr}$ with little change in viscosity, in many samples from bronchorrhoea-but not all-there is a spontaneous increase in viscosity over the first 3-4 hr after the material has been produced.

One can perhaps summarize the behaviour of sputum by distinguishing four 'zones' or regions of the shear rate viscosity plot according to the pattern of behaviour (Reid, 1973b) (Fig. 3).

\section{Origin of bronchial secretion}

The secretion is produced both by the surface epithelium and by the submucosal glands. The submucosal gland includes a collecting duct which may be $1 \mathrm{~mm}$ or so in length and is lined by a special cell type (Meyrick, Sturgess and Reid, 1969), which is high and stuffed with mitochondria. It resembles the duct cell of the salivary gland save that it has not got the striated base. In one gland that was reconstructed thirteen tubules arose from this duct (Fig. 6) and two of them that were reconstructed, showed that the serous cells are always at the ultimate end of the $\mathbb{\infty}$ tubule or in lateral pouchings. This means that the $c$ secretion of the serous cell will always flow over that of the mucous. The ciliated surface epithelium dips $\stackrel{0}{\rightarrow}$ into the opening of the duct for perhaps up to $0.2 \mathrm{~mm}$.

The surface epithelium includes mucous, or goblet, cells (we confine the use of the word 'goblet' to a cell $\frac{\bar{c}}{2}$ distended with mucus secretion and found within the $\stackrel{\mathbb{Q}}{\varrho}$ surface epithelium). Recently the serous cell has been identified within the surface epithelium as well as in $\vec{P}$ the submucosal gland, which means that three? secretory cell types can be distinguished within $\vec{\omega}$ surface epithelium-the goblet or mucous cell, the $\stackrel{\sigma}{\circ}$ serous cell and the Clara cell (Jeffery and Reid, $\mathbb{Z}$ 1975). At least in the rat, it seems that the distribu. 3 . tion is such that the serous cell is mainly present in in central and large airways, the Clara in the peripheral 8 and small ones. The granules of the mucous cell 8 become confluent and if one starts to discharge a $\vec{\infty}$ large amount of secretion may leave the cell as $\omega$ through a tube of toothpaste. From the Clara cell 음 and the serous cell it is individual granules that $\rightarrow$ discharge. In the case of the serous cells in the sub- $\frac{7}{0}$ mucosal gland this discharge may be lateral as well as apical.

The volume of the glands is relatively mucß greater than that of the goblet cells-in the norma. airway $4.0 \mathrm{ml}$ compared with $0.1 \mathrm{ml}$.

\section{Organ culture}

The application of Trowell's method of organ culture (Trowell, 1959) to bronchial wall has contributed to our understanding of the control of secretion from the submucosal glands (Sturgess and Reid, 1972a, b; Meyrick and Reid, 1970, 1975). From surgical specimens a cuff of bronchus is collected in the operating theatre, under sterile conditions. Strips or explants $1 \mathrm{~cm}$ long and $1 \mathrm{~mm}$ wide and deep are cut from the layer superficial to the cartilage. Three such explants are placed together on to a piece of lens tissue, each group being regarded as one experiment. This makes allowance for intra-tissue variation and it is often found necessary to use all three explants to obtain the number of tubules or cells necessary for satisfactory statistical analysis.

The lens tissue with its load of explants is then placed on to a metal raft and organ culture medium is placed under the raft so that the lens tissue is just moistened. To the organ culture medium can be added radioactive precursors of acid glycoprotein and drugs. It is possible to trace the uptake of radioactive precursor into the cell, its synthesis and transport through the cell and its discharge. In the normal gland we find that something like $50 \%$ of cells are secreting at the end of $4 \mathrm{hr}$. The percentage 


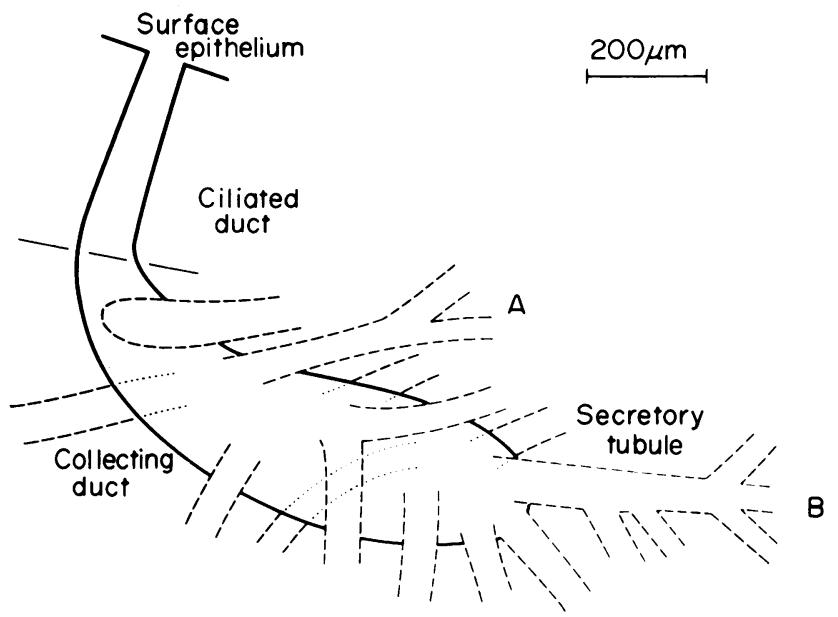

Fig. 6. Reconstruction of submucosal gland (Meyrick, Sturgess \& Reid, 1969) (reproduced by kind permission of the Editor of Thorax).

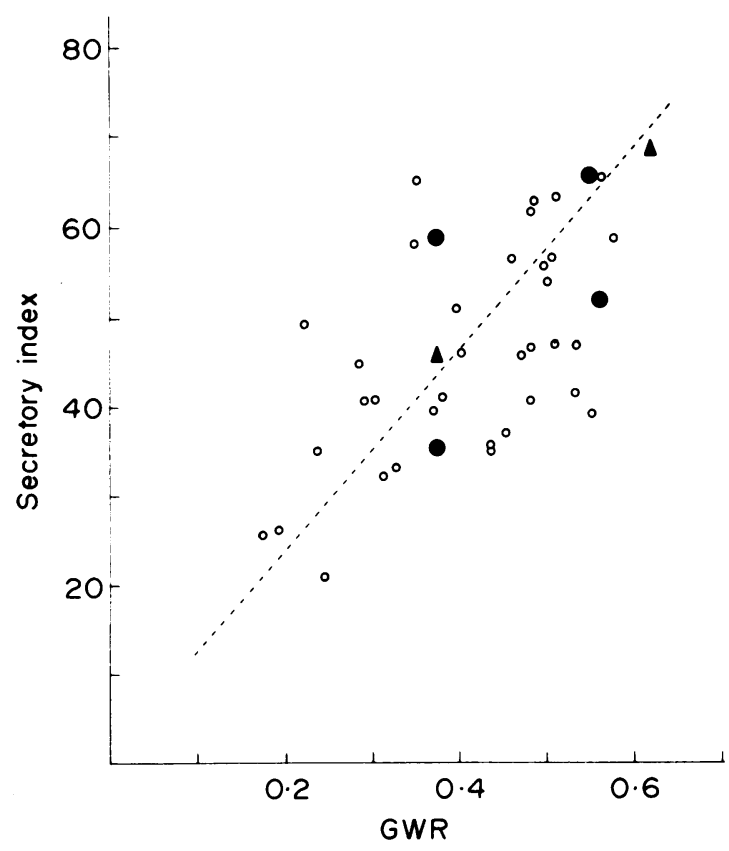

Fig. 7. Secretory Index (percentage of cells secreting at $4 \mathrm{hr}$ ) is significantly correlated with gland size (GWR).

$\boldsymbol{}$, Cystic fibrosis; $\boldsymbol{\Delta}$, bronchiectasis.

of cells secreting at $4 \mathrm{hr}$ we have called the Secretory Index.

A large number of drugs was tested in this way (Sturgess and Reid, 1972b). It is the parasympathetic system that is important in short-term control. Cholinergic drugs increased secretion, atropine reduced it. At no dose, however, was atropine able to suppress secretion completely. The sympathomimetic drugs had no effect. Certain of the metabolic toxins produced inhibition. The steroids did not affect all patients, only four out of thirteen, but in these there was a reduction in secretion that was dose-related in its degree. It seems then, that, to a certain extent, the action of steroids reflects tissue sensitivity.

The Secretory Index (Fig. 7) under control baseline conditions was found to vary widely from patient to patient. It emerged that the hypertrophied gland showed a much higher Secretory Index and also was much more sensitive to stimulation, i.e. it showed a greater increase of Secretory Index for a given dose of drug. The hypertrophied gland was also more difficult to inhibit in that a given dose of atropine produced a lesser degree of inhibition than in the normal gland.

Similar precise quantitative studies have not yet been made on the goblet cells of the surface epithelium under these conditions. Secretion from the surface has not yet been collected separately from that of the gland nor is it possible to distinguish the periciliary liquid layer from the more viscous secretions that lie on the tips of the cilia.

\section{Mucociliary escalator}

Eight epithelial cell types have recently been identified and two mesenchymal, or migratory, cell types superficial to the basement membrane (Jeffery and Reid, 1975).

Two cells can be regarded as basal-the so-called basal cell and the Kultschitsky cell. These two, like all the other epithelial cells, reach the basement membrane, but not the lumen of the airways. 
The basal cell is the 'stem cell' in the large airways. In the small airways it is sufficiently sparse, i.e. less than $1 \%$ of cells, that it would seem that cell multiplication in the peripheral airways occurs by division of a superficial cell. In the large airways the basal cell is commonly seen in division although, particularly under conditions of irritation, superficial cells are also seen in mitosis (Bolduc and Reid, 1975a, b).

The intermediate cell is probably the cell from which the other superficial cells differentiate.

The ciliated cell is found at all levels but becomes relatively more numerous toward the periphery although the cilia become shorter.

The structure of the cilium seems similar throughout the animal kingdom, nine doublets at the periphery and in the centre one special doublet. Understanding of the activity of cilia has increased greatly in recent years so that we now know something of the molecular basis of ciliary activity: it is mediated through two contractile proteins-tubulin and dynein.

At the edge of the cilium, Dr Peter Jeffery found a group of small 'claws' a fraction of a $\mu \mathrm{m}$ in length; this suggests that the cilia exert a 'clawing' effect on the overlying mucus (Jeffery and Reid, 1975). It is of some interest that the conditions that increase the number of goblet cells also increase the number of ciliated cells. He has also been able to show that both serous and Clara cells can, under conditions of irritation by inhaled irritants and drugs, be converted to goblet cells.

The normal airways should be empty save for the periciliary liquid layer maintaining the moist surface. In disease, viscous secretions are present not only in large airways where they may simply contribute to turbulence of air flow but may also be present in the small airways where they may completely block the lumen. The first study to show a relation between viscosity and reduction in $\mathrm{FEV}_{1}$ was carried out by Dr Lopez-Vidriero (1973) in a series of advanced out-patient bronchitics in Dr Citron's clinic at Wandsworth.

In the normal subject the peripheral small airways do not contain mucous or goblet cells to any significant number; it may be that the secretions of the serous and Clara cells are those responsible for the periciliary liquid layer or that this is simply a tissue fluid transudate. On the other hand, under conditions of disease - as in the hypersecretory states of chronic bronchitis-a large number of mucussecreting cells is commonly found in the small airways. Mechanical obstruction can arise from this structural modification.

\section{References}

Bolduc, P. \& ReID, L. (1976a) Mitotic index of the bronchial and alveolar lining of the normal rat lung ${ }^{1-3}$. (In preparation.)

Bolduc, P. \& ReID, L. (1976b) The effect of isoprenaline and pilocarpine on mitotic index and goblet cell number in rat $\frac{\bar{\sigma}}{\bar{S}}$
respiratory epithelium. (In preparation.)

Charman, J., Lopez-Vidriero, M., Keal, E. \& Reid, L. $\Phi$ (1974) The physical and chemical properties of bronchial 응 secretion. British Journal of Diseases of the Chest, 68, 215. ఝి

Iravani, J. \& van As, A. (1972) Mucus transport in the $\overrightarrow{0}$ tracheobronchial tree of normal and bronchitic rats. ? Journal of Pathology, 106, 81.

JEFFERY, P. \& REID, L. (1975) New features of rat airway epithelium. A quantitative and electron microscopic study. $\frac{\mathrm{O}}{8}$ Journal of Anatomy, 120, 295.

LOPEZ-VIDRIERO, M. (1973) Individual and group correlations 3 of sputum viscosity and airways obstruction. Bulletin de Physiopathologie Respiratoire, 9, 339.

Lopez-Vidriero, M., Charman, J., Spiro, S.G., Das, I. \& REID, L. (1975) Bronchorrhoea in a case of alveolar cell oூ carcinoma. Journal of Clinical Pathology, 28, 60.

MeYRICK, B., Sturgess, J.M. \& ReID, L. (1969) A recon- $-\infty$ struction of the duct system and secretory tubules on the human bronchial submucosal gland. Thorax, 24, 729.

MEYRICK, B. \& REID, L. (1970) Ultrastructure of cells in the human bronchial submucosal glands. Journal of Anatomy, $\frac{7}{O}$ 107, 281.

MEYRICK, B. \& REID, L. (1975) In vitro incorporation of $\mathrm{H}^{3}-\overrightarrow{\overrightarrow{0}}$ threonine and $\mathrm{H}^{3}$-glucose by the serous and mucus cells $\mathbb{8} \mathfrak{G}$ the human bronchial submucosal gland: a quantitatiue electron microscopic study. Journal of Cell Biology, 320.

Mitchell-Heggs, P., Palfrey, A.J. \& Reid, L. (1979 Viscosity of normal human synovial fluid. (Abstract.) $\bar{\partial}$ 7th European Congress of Rheumatology, Brighton, 16th March 1971.

Mitchell-Heggs, P., Palfrey, A.J. \& Reid, L. (1974) The ® elasticity of sputum at low shear rates. Biorheology, 11, 417. $\overrightarrow{\vec{A}}$

REID, L. (1970) Chronic bronchitis-A report on mucus research. Proceedings of the Royal Institute of Great Britain, 43, 438.

ReID, L. (1973a) The landing site. In: Airborne Transmission and Airborne Infection (Ed. by J. F. Ph. Hers and K. C. $\bar{\partial}$ Winkler), p. 165. Oosthoek Publishing Company, Utrecht, The Netherlands.

ReID, L. (1973b) Bronchial secretion. Bulletin de Physio- $\frac{0}{3}$ pathologie Respiratoire, 9, 15.

Sturgess, J.M., Palfrey, A.J. \& Reid, L. (1970) The vis- ठิ cosity of bronchial secretion. Clinical Science, 38, 145.

Sturgess, J.M., Palfrey, A.J. \& Reid, L. (1971) Rheological 응 properties of sputum. Rheologica acta, 10, 36.

StURGESS, J. \& REID, L. (1972a) Secretory activity of the $D$ human bronchial mucous glands in vitro. Experimental and Molecular Pathology, 16, 362.

STURGESS, J. \& REID, L. (1972b) An organ culture study of the $\widetilde{N}$ effect of drugs on the secretory activity of the human $N$ bronchial submucosal gland. Clinical Science, 43, 533.

Trowell, O.A. (1959) The culture of mature organs in a $\mathbf{\omega}$ synthetic medium. Problems of maintenance of mature organs in vivo. Experimental Cell Research, 16, 118. 